\title{
Prevalence of Anemia in Children from Latin America and the Caribbean and Effectiveness of Nutritional Interventions: Systematic Review and Meta-Analysis
}

\author{
Lucía Iglesias Vázquez ${ }^{\mathbb{D}}$, Edith Valera, Marcela Villalobos, Mónica Tous and Victoria Arija * \\ Department of Preventive Medicine and Public Health, Faculty of Medicine and Health Science, Universitat \\ Rovira i Virgili, 43201 Reus, Spain; lucia.iglesias@urv.cat (L.I.V.); edith.valera@estudiants.urv.cat (E.V.); \\ marcela.villalobos@estudiants.urv.cat (M.V.); monica.tous@urv.cat (M.T.) \\ * Correspondence: victoria.arija@urv.cat; Tel.: +34-977-759334; Fax: +34-977-759322
}

Received: 21 December 2018; Accepted: 14 January 2019; Published: 16 January 2019

\begin{abstract}
Anemia affects 1.62 billion people worldwide. Latin America and the Caribbean (LAC) comprise several developing countries where children are a population at risk. This systematic review and meta-analysis aimed to estimate the prevalence of anemia in this population. Electronic databases, reference lists, and websites of health ministries were searched until December 2018. Stratified analyses were performed using RevMan5.3 to estimate the overall prevalence of anemia in preschool and school-age children. The effectiveness of nutritional interventions was also evaluated. We included 61 studies from the 917 reviewed, which included 128,311 preschool- and 38,028 school-age children from 21 LAC countries. The number of anemic children was $32.93 \%$ and $17.49 \%$, respectively, demonstrating a significant difference according to age $(p<0.01)$. No difference was observed by gender and only school-age children from low/very low socioeconomic status (SES) $(25.75 \%)$ were more prone to anemia than those from middle SES $(7.90 \%)$. It was not a concern in the Southern Cone but constituted a serious public health problem in the Latin Caribbean. Nutritional interventions reduced the prevalence from $45 \%$ to $25 \%(p<0.01)$. Anemia is still a public health problem for children in LAC countries. National surveys should include school-age children. Further nutritional interventions are required to control anemia.
\end{abstract}

Keywords: anemia; school-age children; preschool children; Latin America; Caribbean; developing countries; low- and middle-income countries; meta-analysis

\section{Introduction}

According to the estimates of international organizations, about 1.62 billion people in the world suffer from anemia [1], which constitutes a global public health problem in both developing and industrialized countries. However, the prevalence of anemia is higher in developing areas where pregnant women, women of childbearing age, and young children are especially vulnerable [2]. Anemia has a multifactorial etiology and multiple factors frequently act simultaneously; in this regard, sociodemographic conditions have been strongly associated with the prevalence of anemia, especially in low income countries [2,3].

Anemia during childhood has been linked to growth delay, high risk of infections, and poor cognitive and motor development $[2,4,5]$. In addition, the long-term consequences of anemia in infancy may also compromise social interaction and work productivity later in life $[2,6,7]$. Therefore, anemia affects not only individual quality of life but also the social and economic development of the country, a particularly important issue in developing economies $[2,7,8]$.

Latin America and the Caribbean (LAC) includes several countries with low or very low socioeconomic status (SES), one of the factors that most predisposes children to having a high risk 
of malnutrition and anemia despite the effort of some governments in the promotion of nutritional interventions [2]. According to a recent systematic review [9], the prevalence of anemia in children under 5 years old ranged in LAC countries from $7.6 \%$ in Costa Rica to 65\% in Haiti. Regarding prevalence in school-age children, data are, however, scarce in the literature [4].

The knowledge of the prevalence of anemia and the associated sociodemographic conditions allow us to identify the main risk factors, which will be helpful to prioritize prevention strategies. Therefore, we present a systematic review and meta-analysis of the prevalence of anemia in preschooland school-age children in LAC countries according to their age, gender, SES, and region where they live. The effectiveness of nutritional interventions on the prevalence of anemia was also evaluated.

\section{Materials and Methods}

\subsection{Literature Search}

The systematic review was undertaken following the Meta-analysis of Observational Studies in Epidemiology (MOOSE) guidelines [10]. The electronic databases PubMed, Scopus, and SciELO were searched independently by two authors (LIV and EV) up to December 2018 for studies that reported the prevalence of anemia in children from LAC countries. The search strategy used combinations of terms, including Medical Subject Headings, both in British English (listed here) and American spelling. These terms were anemia, iron deficiency, iron status, ferritin, child, childhood, preschool, school-age children, Latin America, South America and Caribbean. There were no restrictions in terms of language or year of publication. The reference lists of original studies and reviews were searched looking for additional studies of interest. We also searched for national surveys on health and nutritional status through the websites of health ministries, the Demographic and Health Surveys (DHS) Program (www.dhsprogram.com), the United Nations Children's Fund (UNICEF) Multiple Indicator Cluster Surveys (MICS) program (http:/ / mics.unicef.org/surveys), and the WHO Vitamin and Mineral Nutrition Information System (VMNIS) (http:/ / www.who.int/vmnis/database/en/).

The titles and abstracts of the search results were assessed and the full-texts of the potentially relevant articles were read carefully. Those that met the following inclusion criteria were included: (a) observational studies or national surveys that report the prevalence of anemia in preschool children (under 5 years) and school-age children (6-12 years); (b) anemia defined according to the WHO indications, internationally recognized, or very close to them; (c) studies carried on in LAC; (d) national or representative studies $(n \geq 100)$, except for the meta-analysis on effectiveness of nutritional interventions that included all available literature regardless of the sample size. Case reports, comments, editorials, letters, reviews, systematic reviews and meta-analysis, and those studies that assessed children with some disease were excluded from the selection process.

To discuss the public health problem posed by anemia for children, some importance categories were defined, according to WHO recommendations, as follows: not a public health problem when prevalence was under 4.9\%; mild public health problem for prevalence between 5 and $19.9 \%$; moderate public health problem for prevalence between 20 and $39.9 \%$, and severe public health problem when prevalence exceeded $40 \%$ [1].

\subsection{Data Extraction and Quality Assessment}

Data on the first author's surname, year of publication, country, SES, study design, total sample size, number of children with anemia, prevalence of anemia, and 95\% confidence interval (CI) of anemia were extracted from all the included studies. Prevalence of anemia and 95\% CI before and after the nutritional interventions were also extracted for those articles that reported them. Data extraction was performed independently by LIV, MV, and EV.

Methodological quality of the studies was assessed using the Newcastle-Ottawa scale [11], following the recommendation of the Cochrane Non-Randomized Studies Methods Working Group. 
This scale categorizes the final score in good, fair, and poor quality according to three domains of the evaluated studies: selection, comparability, and outcome.

\subsection{Data Analysis}

The prevalence of anemia (\%) and standard error (SE) reported by each study were used to obtain the overall prevalence of anemia in children. In studies where the SE was not reported, it was calculated based on the prevalence and sample size. When a study examined the same population at different ages, data from older children was included in the meta-analysis.

A random-effect meta-analysis was undertaken by using the Review Manager 5.3 software (The Cochrane Collaboration, Copenhagen, Denmark) by using the inverse-variance method. Heterogeneity was assessed by calculating $\mathrm{I}^{2}$ [12]. Results were visualized using forest plots and the potential publication bias using funnel plots. Sensitivity analyses were also conducted to assess the robustness of the results by evaluating whether they could have been markedly affected by a single study. Statistical significance was set at $p<0.05$ for all the analyses.

Stratified analyses were performed by: age (preschool- vs school-age children), gender (boy vs girl), SES (middle vs low or very low), area of residence (urban vs rural), and LAC region, including Mexico, Central America, Latin Caribbean, Andean subregion, Brazil, Southern Cone and non-Latin Caribbean. As a complementary analysis, the stratification by gender was also applied to children between 9 and 12 years old under the hypothesis that girls could already menstruate at these ages, which could make a difference between boys and girls. Furthermore, a comparative analysis of the prevalence of anemia before and after the application of nutritional intervention programs was performed to evaluate their effectiveness. In this section, additional sub-analyses were done by selecting the interventions at the national or regional level separately.

\section{Results}

The selection process of included studies is depicted in Figure 1. The search strategy performed in the PubMed, Scopus, and SciELO databases identified 917 publications that were firstly scrutinized by title and abstract; the full-texts of 95 articles were reviewed, of which 56 were excluded for the following reasons: children with any disease, lack of data on outcomes of interest, and non-representative sample was assessed. Twenty articles were additionally included to the selection process. Finally, the meta-analysis of prevalence of anemia included 54 studies with 128,311 preschool children and 38,028 school-age children from 21 LAC countries, evaluated between 1997 and 2018. The effectiveness of nutritional interventions was assessed in more than 6600 children from 10 LAC countries. 


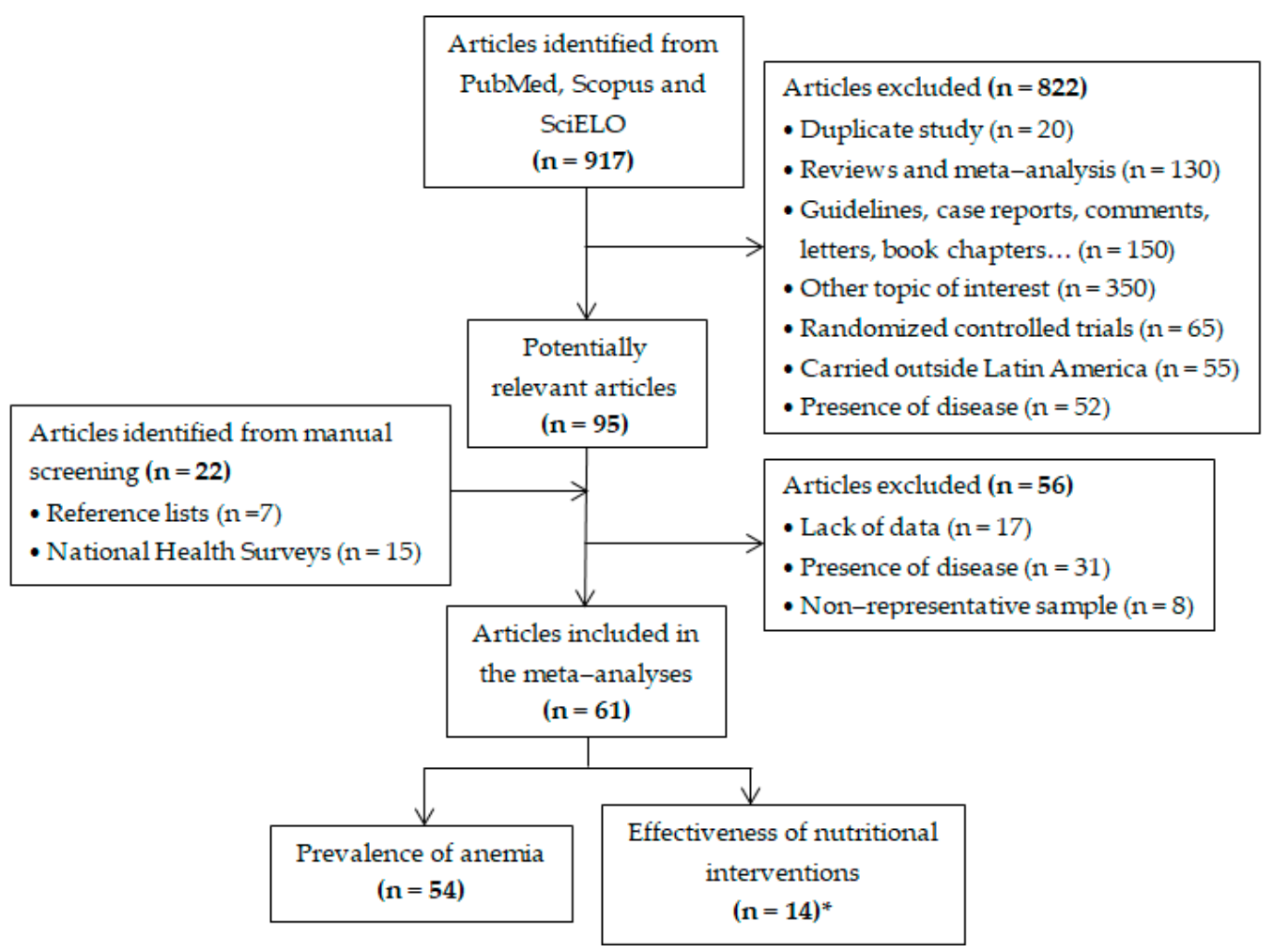

Figure 1. Flowchart of study selection. * This section includes seven new studies that were not present in the meta-analyses of prevalence of anemia.

\subsection{Study Characteristics}

Tables 1 and 2 present the information of the included studies for preschool and school-age children, respectively. Most of the studies used cross-sectional design, although one was a retrospective study [13], thirteen were national surveys about health, diet, and lifestyle [14-26], and five more were based on national surveys reports [27-31]. The studies were performed in Guyana [20], Argentina [29,32,33], Bolivia [26], Brazil [18,28,34-50], Chile [51,52], Colombia [27], Costa Rica [53,54], Cuba [55,56], Dominican Republic [24,25], Ecuador [16,57], Uruguay [58], Jamaica [59], Dominica [13], El Salvador [23], Guatemala [22], Haiti [17,60], Honduras [19], Mexico [30,31,61,62], Nicaragua [21], Panama [14], and Peru [15,63-66]. In relation to the SES, there were 25 studies conducted on middle income countries and the other 29 performed on low or very low-income countries. As to the methodological quality, good quality was reported in 34 studies and fair quality in the other 20 studies, according to Newcastle-Ottawa scale. 
Table 1. Characteristics of studies that assessed preschool children (under 5 years).

\begin{tabular}{|c|c|c|c|c|c|c|c|c|c|}
\hline \multirow{2}{*}{ Author } & \multirow{2}{*}{ Year } & \multirow{2}{*}{ Country } & \multirow{2}{*}{ SES } & \multirow{2}{*}{ Study Design } & \multirow{2}{*}{ Sample Size $(n)$} & \multirow{2}{*}{$\begin{array}{c}\text { Anemic } \\
\text { Children }(n)\end{array}$} & \multicolumn{2}{|c|}{ Anemia } & \multirow{2}{*}{$\begin{array}{l}\text { Quality of } \\
\text { Studies }\end{array}$} \\
\hline & & & & & & & $\%$ & $95 \% \mathrm{CI}$ & \\
\hline CFNI/PAHO_Jamaica [59] & 1998 & Jamaica & Low & Cross-sectional & 272 & 131 & 48.20 & $42.26-54.14$ & Fair \\
\hline Neuman NA, et al. [43] & 2000 & Brazil & Middle & Cross-sectional & 468 & 284 & 60.60 & $56.17-65.03$ & Good \\
\hline Osório MM, et al. [44] & 2001 & Brazil & Very low & Cross-sectional & 777 & 318 & 40.90 & $37.44-44.36$ & Good \\
\hline Rivera JA, et al. [61] & 2004 & Mexico & Low & Cross-sectional & 595 & 154 & 25.80 & $22.28-29.32$ & Good \\
\hline Assis AM, et al. [45] & 2004 & Brazil & Middle & Cross-sectional & 603 & 279 & 46.30 & $42.32-50.28$ & Good \\
\hline Morais MB, et al. [46] & 2005 & Brazil & Very low & Cross-sectional & 108 & 70 & 64.80 & $55.79-73.81$ & Fair \\
\hline Ministry of health of Panama [14] & 2006 & Panama & Very low & National Survey & 373 & 156 & 41.80 & $36.79-46.81$ & Fair \\
\hline Brooker S, et al. [47] & 2007 & Brazil & Very low & Cross-sectional & 139 & 44 & 31.65 & $23.92-39.38$ & Fair \\
\hline EMMUS IV [17] & 2007 & Haiti & Low & National Survey & 4142 & 2599 & 60.60 & $59.11-62.09$ & Fair \\
\hline Duque $X$, et al. [31] & 2007 & Mexico & Middle & Cross-sectional * & 4957 & 986 & 19.90 & 18.79-21.01 & Good \\
\hline Vieira AC, et al. [48] & 2007 & Brazil & Very low & Cross-sectional & 153 & 85 & 55.60 & $47.73-63.47$ & Fair \\
\hline SIVIN 2007 [21] & 2008 & Nicaragua & Very low & National Survey & 1466 & 295 & 20.10 & $18.05-22.15$ & Good \\
\hline PNDS 2006 [18] & 2009 & Brazil & Middle & National Survey & 3455 & 721 & 20.86 & $19.51-22.21$ & Good \\
\hline Durán P, et al. [29] & 2009 & Argentina & Middle & Cross-sectional * & 30,514 & 5035 & 16.50 & $16.08-16.92$ & Good \\
\hline GDSH 2009 [20] & 2009 & Guyana & Middle & National Survey & 1349 & 316 & 23.40 & $21.14-25.66$ & Good \\
\hline Oliveira CSM, et al. [49] & 2011 & Brazil & Middle & Cross-sectional & 429 & 246 & 57.30 & $52.62-61.98$ & Good \\
\hline Castro TG, et al. [50] & 2011 & Brazil & Middle & Cross-sectional & 617 & 180 & 29.20 & $25.61-32.79$ & Good \\
\hline Leal LP, et al. [34] & 2011 & Brazil & Middle & Cross-sectional & 1403 & 476 & 33.92 & $31.44-36.40$ & Good \\
\hline Cardoso MA, et al. [35] & 2012 & Brazil & Middle & Cross-sectional & 526 & 111 & 21.10 & $17.61-24.59$ & Good \\
\hline Rocha DS, et al. [36] & 2012 & Brazil & Middle & Cross-sectional & 312 & 102 & 32.80 & $27.59-38.01$ & Good \\
\hline Brito A, et al. [51] & 2012 & Chile & Middle & Cross-sectional & 224 & 12 & 5.40 & $2.44-8.36$ & Fair \\
\hline Huamán-Espino L, et al. [65] & 2012 & Peru & Very low & Cross-sectional & 714 & 366 & 51.30 & $47.63-54.97$ & Good \\
\hline ENSANUT-ECU 2012 [16] & 2012 & Ecuador & Middle & National Survey & 1913 & 356 & 18.60 & $16.86-20.34$ & Fair \\
\hline Oliveira AP, et al. [37] & 2013 & Brazil & Middle & Cross-sectional & 980 & 363 & 37.00 & $33.98-40.02$ & Good \\
\hline Silla L, et al. [38] & 2013 & Brazil & Middle & Cross-sectional & 2186 & 992 & 45.40 & $43.31-47.49$ & Good \\
\hline ENDESA 2011-2012 [19] & 2013 & Honduras & Very low & National Survey & 10,681 & 3097 & 29.00 & $28.14-29.86$ & Good \\
\hline Brito A, et al. [52] & 2013 & Chile & Very low & Cross-sectional & 320 & 44 & 13.75 & $9.98-17.52$ & Good \\
\hline Leite MS, et al. [28] & 2013 & Brazil & Very low & Cross-sectional * & 5397 & 2763 & 51.20 & $49.87-52.53$ & Good \\
\hline National Micronutrients Survey [24] & 2014 & Dominican Republic & Low & National Survey & 772 & 217 & 28.10 & $24.93-31.27$ & Fair \\
\hline ENS 2014 [23] & 2014 & El Salvador & Very low & National Survey & 5862 & 1327 & 22.64 & $21.57-23.71$ & Good \\
\hline Oliveira TSC, et al. [39] & 2014 & Brazil & Middle & Cross-sectional & 373 & 143 & 38.30 & $33.37-43.23$ & Good \\
\hline Sarmiento OL, et al. [27] & 2014 & Colombia & Middle & Cross-sectional * & 7725 & 2124 & 27.50 & $26.50-28.50$ & Good \\
\hline Saraiva BC, et al. [40] & 2014 & Brazil & Middle & Cross-sectional & 692 & 109 & 15.70 & $12.99-18.41$ & Good \\
\hline Pita GM, et al. [55] & 2014 & $\begin{array}{l}\text { Cuba } \\
\text { Cuba }\end{array}$ & Low & Cross-sectional & 2204 & 573 & 26.00 & $24.17-27.83$ & Good \\
\hline Vasconcelos PN, et al. [41] & 2014 & Brazil & Middle & Cross-sectional & 646 & 135 & 20.90 & $17.76-24.04$ & Fair \\
\hline Iannotti L, et al. [60] & 2015 & Haiti & Low & Cross-sectional & 182 & 128 & 70.30 & $63.66-76.94$ & Good \\
\hline Rodríguez-Zúñiga MI, et al. [66] & 2015 & Peru & Low & Cross-sectional & 473 & 137 & 29.00 & $24.91-33.09$ & Good \\
\hline Martorell R, et al. [53] & 2015 & Costa Rica & Very low & Cross-sectional & 403 & 16 & 4.00 & $2.09-5.91$ & Fair \\
\hline ENDES $2016[15]$ & 2017 & Peru & Low & National Survey & 10,060 & 3350 & 33.30 & $32.38-34.22$ & Good \\
\hline EDSA 2016 [26] & 2017 & Boliva & Low & National Survey & 1526 & 819 & 53.70 & $51.20-56.20$ & Fair \\
\hline ENSMI 2014-2015 [22] & 2017 & Guatemala & Low & National Survey & 11,164 & 3617 & 32.40 & $31.53-33.27$ & Good \\
\hline Robles BN, et al. [13] & 2017 & Dominica & Very low & Retrospective & 635 & 123 & 19.30 & $16.23-22.37$ & Good \\
\hline Barquero MS, et al. [54] & 2018 & Costa Rica & Very low & Cross-sectional & 1291 & 111 & 8.60 & 7.07-10.13 & Fair \\
\hline Cruz-Góngora V, et al. [30] & 2018 & Mexico & Middle & Cross-sectional * & 9094 & 2446 & 26.90 & $25.99-27.81$ & Good \\
\hline Assandri E, et al. [58] & 2018 & Uruguay & Middle & Cross-sectional & 136 & 45 & 33.00 & $25.10-40.90$ & Fair \\
\hline
\end{tabular}

SES: socioeconomical status; * data from national survey. 
Table 2. Characteristics of studies that assessed schoolchildren (5-12 years).

\begin{tabular}{|c|c|c|c|c|c|c|c|c|c|}
\hline \multirow{2}{*}{ Author } & \multirow{2}{*}{ Year } & \multirow{2}{*}{ Country } & \multirow{2}{*}{ SES } & \multirow{2}{*}{ Study Design } & \multirow{2}{*}{$\begin{array}{l}\text { Sample } \\
\text { Size }(n)\end{array}$} & \multirow{2}{*}{$\begin{array}{c}\text { Anemic } \\
\text { Children }(n)\end{array}$} & \multicolumn{2}{|c|}{ Anemia } & \multirow{2}{*}{$\begin{array}{c}\text { Quality of } \\
\text { Studies }\end{array}$} \\
\hline & & & & & & & $\%$ & $95 \%$ CI & \\
\hline Quizhpe E, et al. [57] & 2003 & Ecuador & Middle & Cross-sectional & 592 & 98 & 16.60 & $13.60-19.60$ & Good \\
\hline Monárrez-Espino J, et al. [62] & 2004 & Mexico & Very low & Cross-sectional & 331 & 43 & 13.00 & $9.38-16.62$ & Fair \\
\hline Reboso J, et al. [56] & 2005 & Cuba & Low & Cross-sectional & 100 & 22 & 22.00 & $13.88-30.12$ & Fair \\
\hline Ministry of health of Panama [14] & 2006 & Panama & Very low & National Survey & 788 & 50 & 6.30 & $4.60-8.00$ & Fair \\
\hline Winocur D, et al. [32] & 2007 & Argentina & Middle & Cross-sectional & 323 & 8 & 2.50 & $0.80-4.20$ & Good \\
\hline Brooker S, et al. [47] & 2007 & Brazil & Very low & Cross-sectional & 301 & 32 & 10.63 & $7.15-14.11$ & Fair \\
\hline ENSANUT-ECU 2012 [16] & 2012 & Ecuador & Middle & National Survey & 4443 & 156 & 3.50 & $2.96-4.04$ & Fair \\
\hline Cardoso MA, et al. [35] & 2012 & Brazil & Middle & Cross-sectional & 585 & 40 & 6.80 & $4.76-8.84$ & Good \\
\hline ENM 2012 [25] & 2013 & Dominican Republic & Low & National Survey & 654 & 119 & 18.20 & $15.24-21.16$ & Fair \\
\hline Sarmiento OL, et al. [27] & 2014 & Colombia & Middle & Cross-sectional * & 7906 & 640 & 8.10 & $7.50-8.70$ & Good \\
\hline Rodríguez-Zúñiga MJ, et al. [66] & 2015 & Peru & Low & Cross-sectional & 1.438 & 905 & 62.90 & $60.40-65.40$ & Good \\
\hline Cabada MN, et al. [63] & 2015 & Peru & Very low & Cross-sectional & 192 & 70 & 36.50 & $29.69-43.31$ & Fair \\
\hline Iannotti L, et al. [60] & 2015 & Haiti & Low & Cross-sectional & 753 & 509 & 67.59 & $64.25-70.93$ & Good \\
\hline Aparco JP, et al. [64] & 2016 & Peru & Low & Cross-sectional & 808 & 96 & 11.90 & $9.67-14.13$ & Fair \\
\hline Ferreira HS, et al. [42] & 2016 & Brazil & Middle & Cross-sectional & 1547 & 144 & 9.30 & $7.85-10.75$ & Good \\
\hline Barquero MS, et al. [54] & 2018 & Costa Rica & Very low & Cross-sectional & 912 & 55 & 6.00 & $4.46-7.54$ & Fair \\
\hline Cruz-Góngora V, et al. [30] & 2018 & Mexico & Middle & Cross-sectional * & 15,993 & 1999 & 12.50 & $11.99-13.01$ & Good \\
\hline Lázaro L, et al. [33] & 2018 & Argentina & Middle & Cross-sectional & 362 & 16 & 4.40 & $2.29-6.51$ & Fair \\
\hline
\end{tabular}

SES: socioeconomical status; ${ }^{*}$ data from national survey. 
With regard to intervention programs designed to address the prevalence of anemia in the LAC countries, the meta-analysis evaluated 14 studies, seven of them exclusively included for that purpose. National plans were carried out in Costa Rica [53], Cuba [55], Dominican Republic (School Feeding Program) [25], Chile (National Complementary Feeding Program) [52], Ecuador (Mi Papilla) [67], and Mexico (Oportunidades) [61]. They implemented nutritional interventions and improvements in health services, especially targeting infants and school-age children. These national plans mostly arose between 1997 and 2000 and most of them routinely provided food fortified with micronutrients, including iron-supplemented formula milk, papilla, or snacks that children should consume at home. In addition, some of them had mandatory sessions on nutrition and health education aimed at mothers or those responsible for children [61]. In Peru, the effectiveness of supplementation with the multimicronutrient Chispitas ${ }^{\circledR}$ in children under 3 years old was evaluated in two regions, Apurímac $(n=714)$ [65] and Ventanilla $(n=30)$ [68], after 6 months of intervention. Also in Peru, an educational and nutritional project [69] was implemented at the regional level between 2004 and 2007 for the prevention of anemia in children under 5 years of age. Finally, randomized controlled trials conducted in Bolivia [70], Haiti [60,71], Brazil [72], and Mexico [73] acted as short-term nutritional interventions based on iron fortification in preschool and school-age children.

\subsection{Prevalence of Anemia in Children}

After performing the systematic review, we observed that the prevalence of anemia ranged from $4 \%$ in Costa Rica [53] to $70.30 \%$ in Haiti [60] for preschool children and from $2.5 \%$ in Argentina [32] to $67.59 \%$ also in Haiti [60]. The overall prevalence of anemia in children under 12 years measured with a random effects model was $28.56 \%$ (95\% CI: 25.17, 31.95), as it is shown in Figure 2.

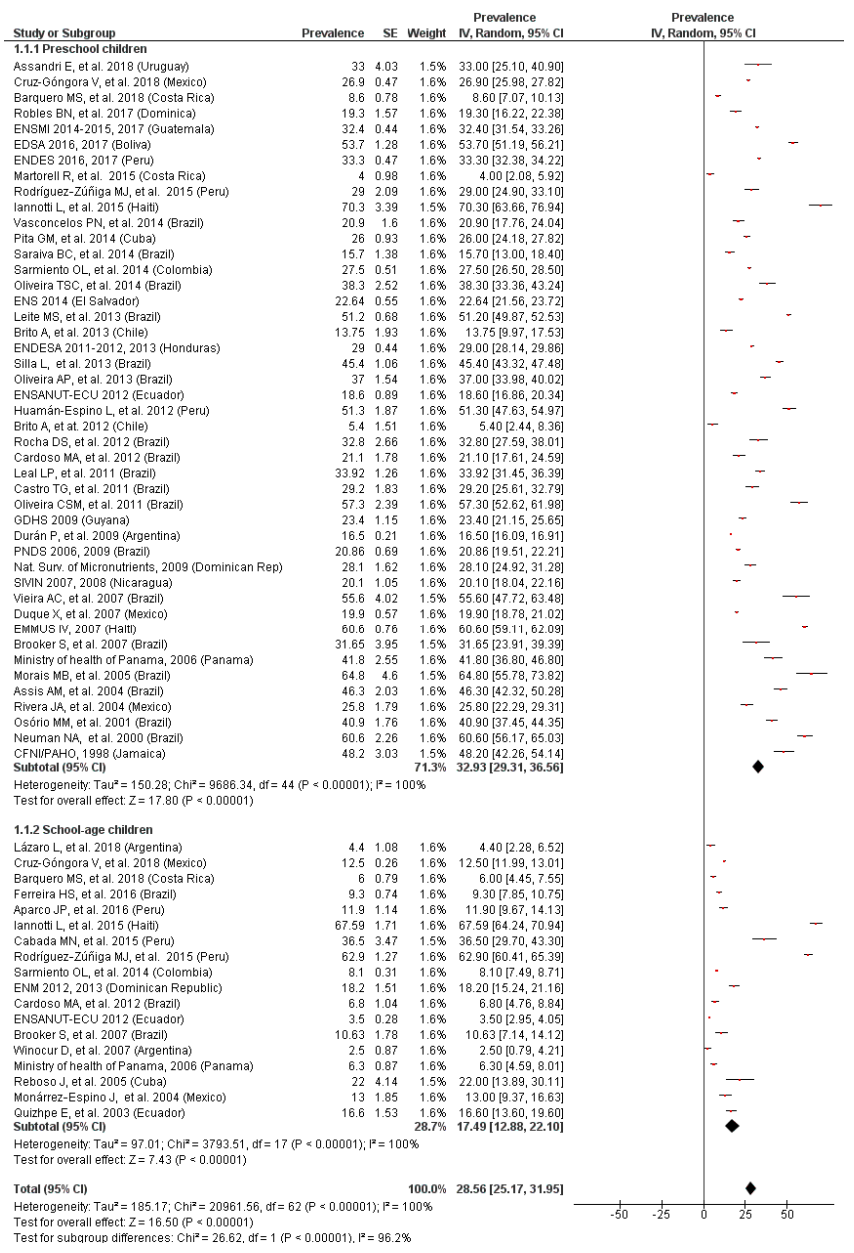

Figure 2. Prevalence of anemia by age. 


\subsection{Prevalence of Anemia by Age}

The stratified analysis by age (Figure 2) highlighted that prevalence of anemia was statistically significant $(p<0.01)$ and higher in preschool children $(32.93 \% ; 95 \%$ CI: $29.31,36.56)$ than in school-age children $(17.49 \%$; $95 \%$ CI: $12.88,22.10)$. The heterogeneity was high $\left(\mathrm{I}^{2}=96.2 \%\right)$. Visual inspection of the funnel plot showed that there was asymmetry, which shows the possibility of publication bias. The sensitivity analyses did not show any substantial variation in the overall results.

\subsection{Prevalence of Anemia by Gender}

According to the presented results, no differences were observed between boys and girls in the meta-analyses of the subsets of studies with data on gender for preschool- (Figure 3) or school-age children (Figure 4). The overall prevalence of anemia was, therefore, $33.35 \%$ and $14.05 \%$ for preschool and school-age boys, respectively, and a bit smaller for their female counterparts $(32.41 \%$ and $12.95 \%$, respectively).

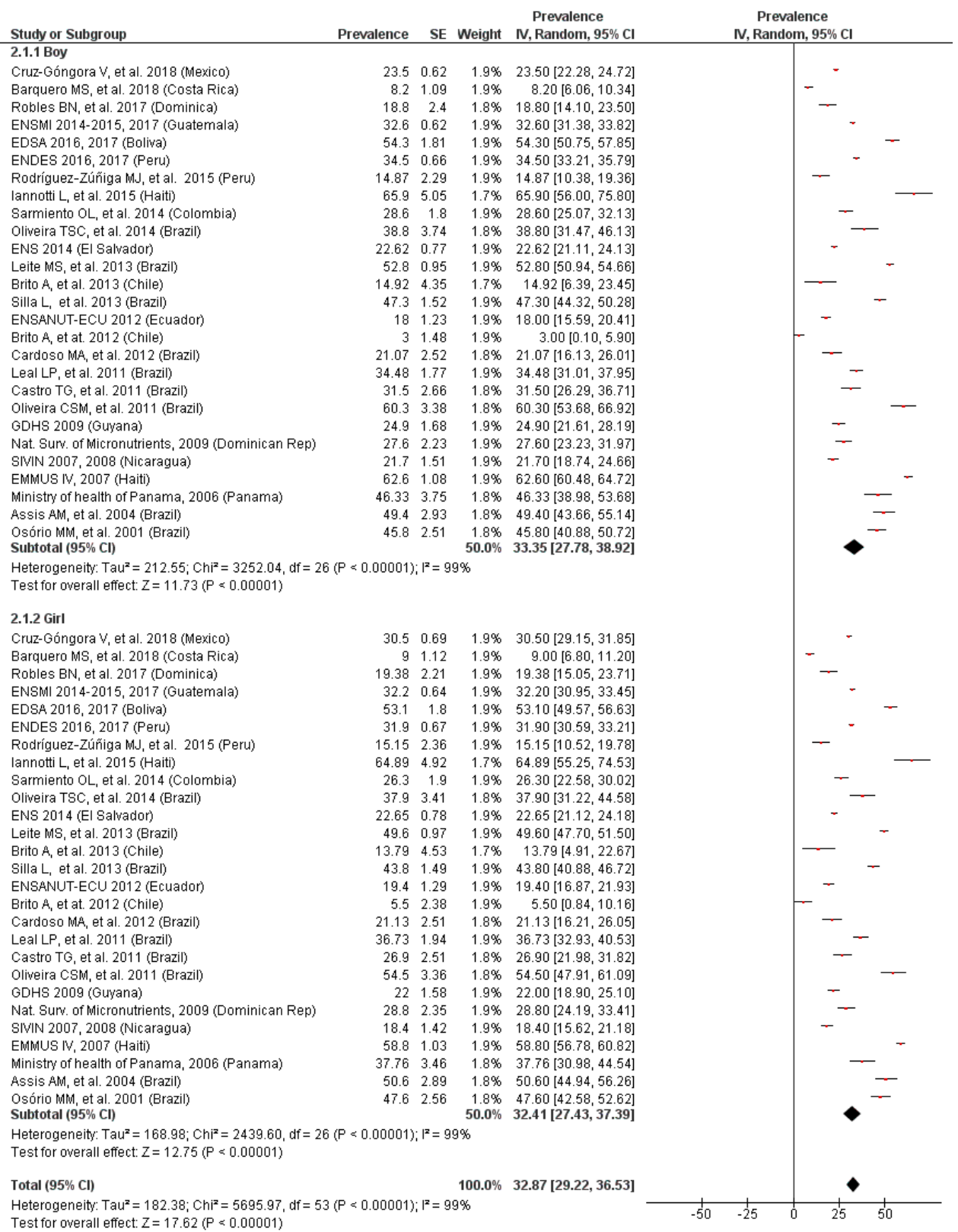

Test for subqroup differences: $\mathrm{Ch}^{2}=0.06, \mathrm{df}=1(\mathrm{P}=0.81), \mathrm{I}^{\mathrm{2}}=0 \%$

Figure 3. Prevalence of anemia in preschool children by gender. 


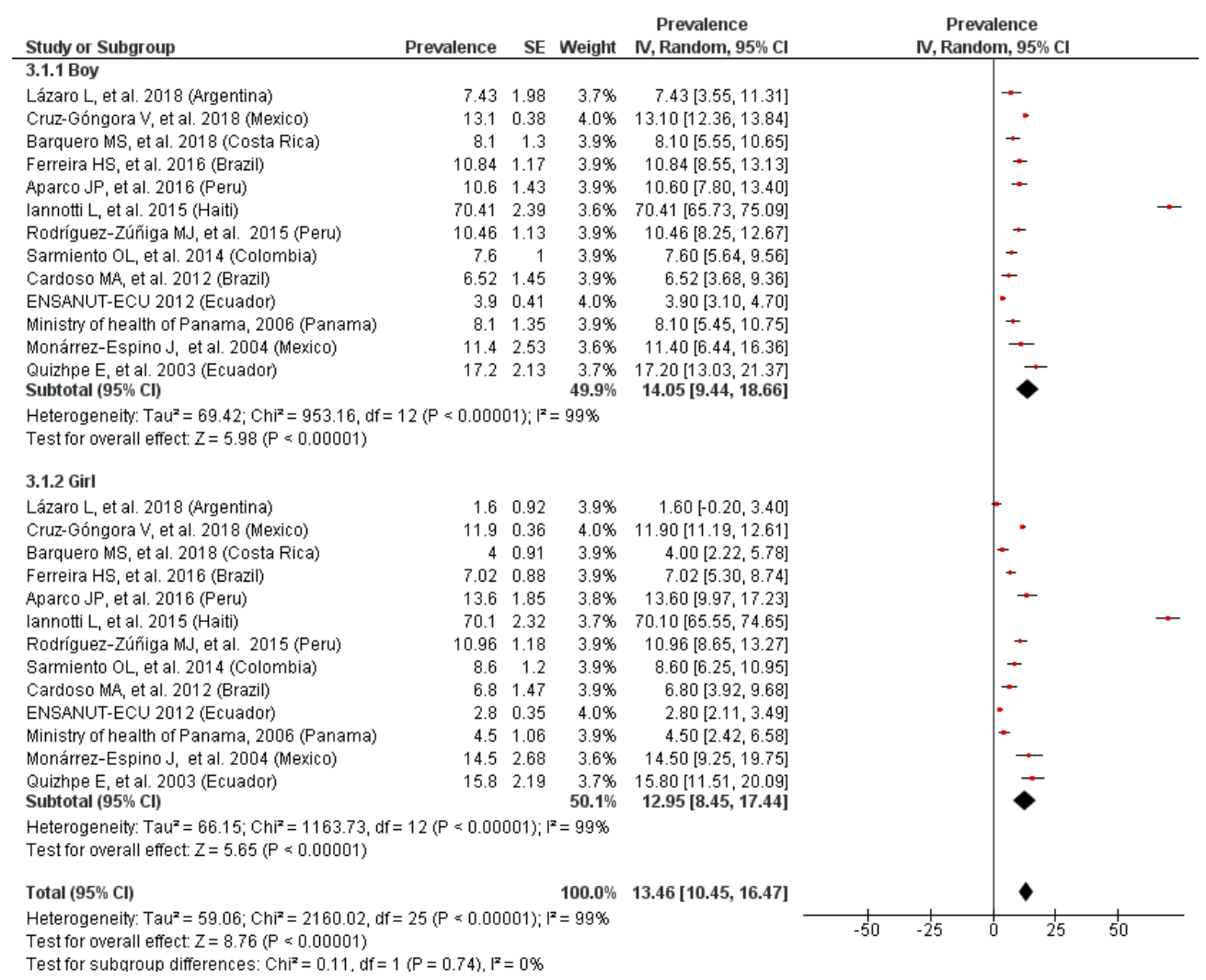

Figure 4. Prevalence of anemia in school-age children by gender.

The prevalence of anemia was also not different $(p=0.93)$ between boys $(19.84 \%$; $95 \%$ CI: 7.43 , $32.25)$ and girls $(19.07 \%$; $95 \%$ CI: $6.71,31.43)$ aged 9 to 12 years, evaluated in more than 3000 individuals (not shown).

The heterogeneity was null for these comparisons but possibly publication bias exists, visualized in an asymmetric funnel plot. The overall results did not change substantially after carrying out the sensitivity analyzes.

\subsection{Prevalence of Anemia by SES}

The subgroup analyses according to SES of children showed a statistically significant difference in the prevalence of anemia in school-age children $(p=0.02)$ but not in preschoolers $(p=0.11)$. However, for both preschool and school-age children, the overall prevalence of anemia was higher in low or very low SES areas (35.47\% and 25.75\%) than in those of middle SES (29.82\% and 7.90\%) (Figures 5 and 6).

There was a fair and high heterogeneity $\left(\mathrm{I}^{2}=61.5 \%\right.$ and $\left.\mathrm{I}^{2}=81.6 \%\right)$ in the analysis of preschool and school-age children, respectively, and both funnel plots showed asymmetry, assuming publication bias. No substantial variation was noticed in the overall results following the sensitivity analyses.

\subsection{Prevalence of Anemia by Area of Residence}

No statistically significant differences were found in the prevalence of anemia in the stratified analysis according to the area of residence (rural or urban) in children of preschool age or school-age $(p=0.38$ and $p=0.42$, respectively). However, at both ages, prevalence was higher in rural than in urban areas: for preschool children, the percentages were $37.82 \%(95 \% \mathrm{CI}: 30.43,45.21)$ vs. $33.83 \%$ (95\%CI: $28.79,38.88)$, respectively, and for school-age children, $25.87 \%$ (95\%CI: $6.50,45.25)$ vs. $16.86 \%$ (95\%CI: 6.93, 26.80), respectively.

The heterogeneity was null for these comparisons but possibly publication bias exists. The overall results did not change substantially after carrying out the sensitivity analyses (not shown). 


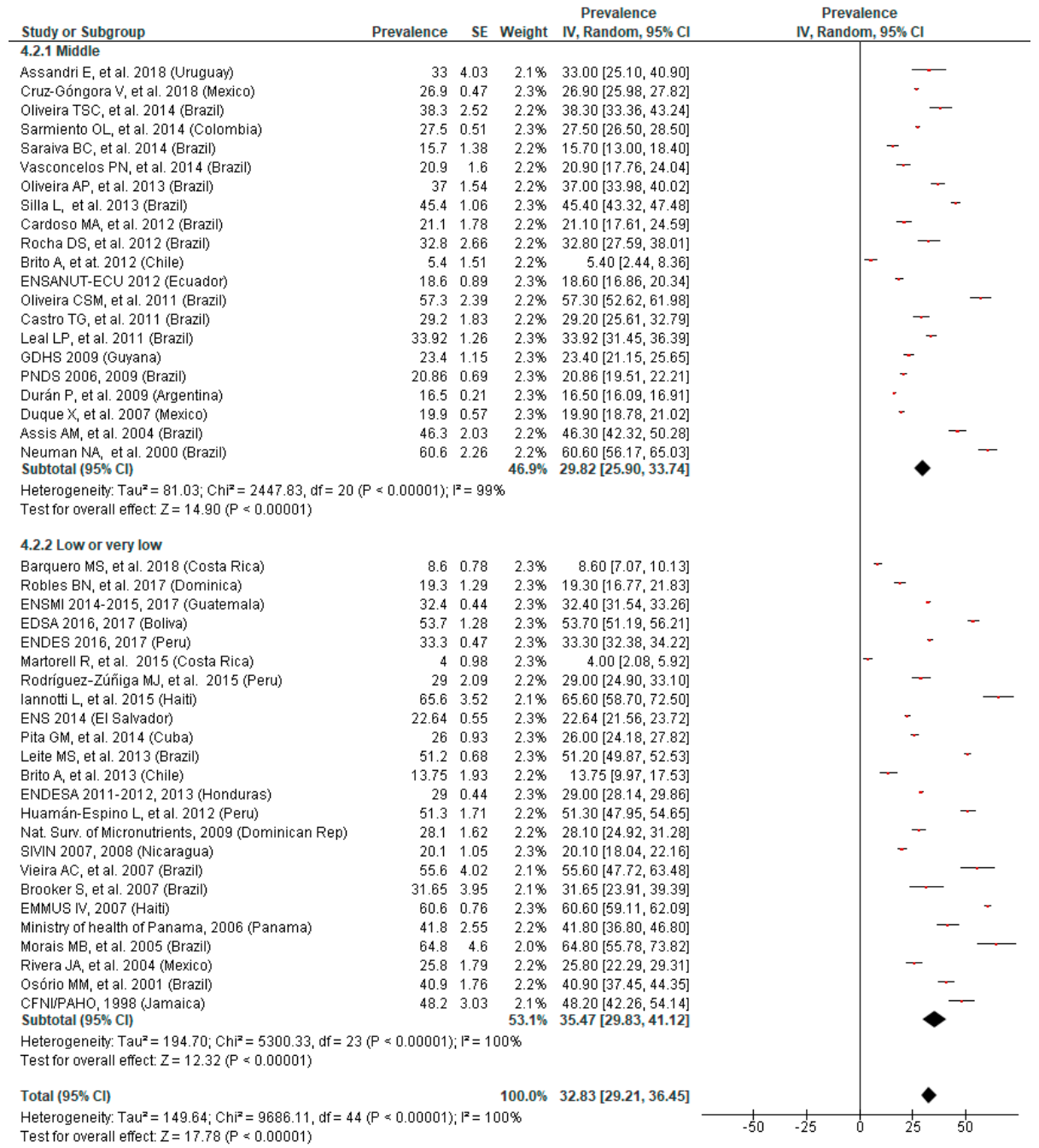

Test for overall effect. $Z=17.78(P<0.00001)$

Figure 5. Prevalence of anemia in preschool children by socioeconomic status.

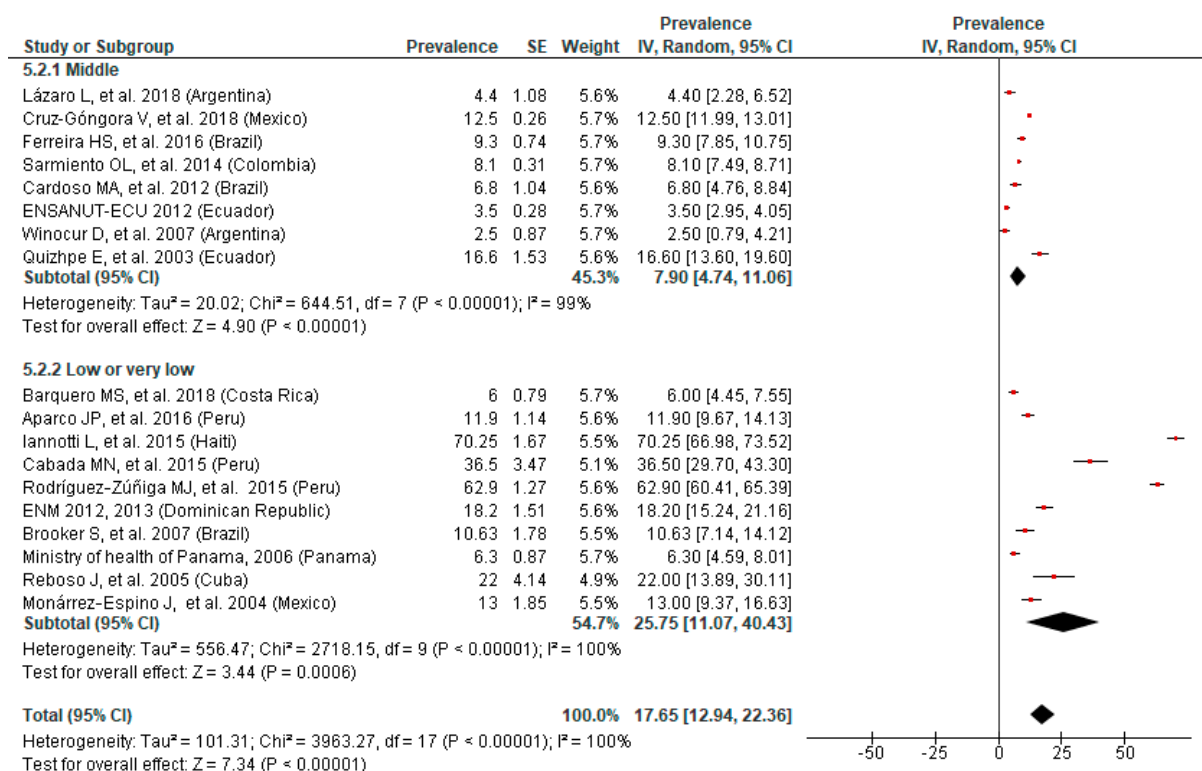
Test for overall effect: $Z=7.34(P<0.00001)$

Test for subqroup differences: $\mathrm{Chi}^{2}=5.43, \mathrm{df}=1(\mathrm{P}=0.02), \mathrm{I}^{2}=81.6 \%$

Figure 6. Prevalence of anemia in school-age children by socioeconomic status. 


\subsection{Prevalence of Anemia by LAC Region}

A statistically significant difference $(p<0.01)$ in the prevalence of anemia was observed from the stratified analyses by LAC region (Figures 7 and 8). The highest rate of anemia was in Latin Caribbean countries, while the Southern Cone region showed the lowest prevalence, regardless of the age of the children. The heterogeneity was high in both analyses and asymmetric funnel plots, suggesting that there was publication bias. No substantial variations in the overall results were shown when the sensitivity analyses were conducted.

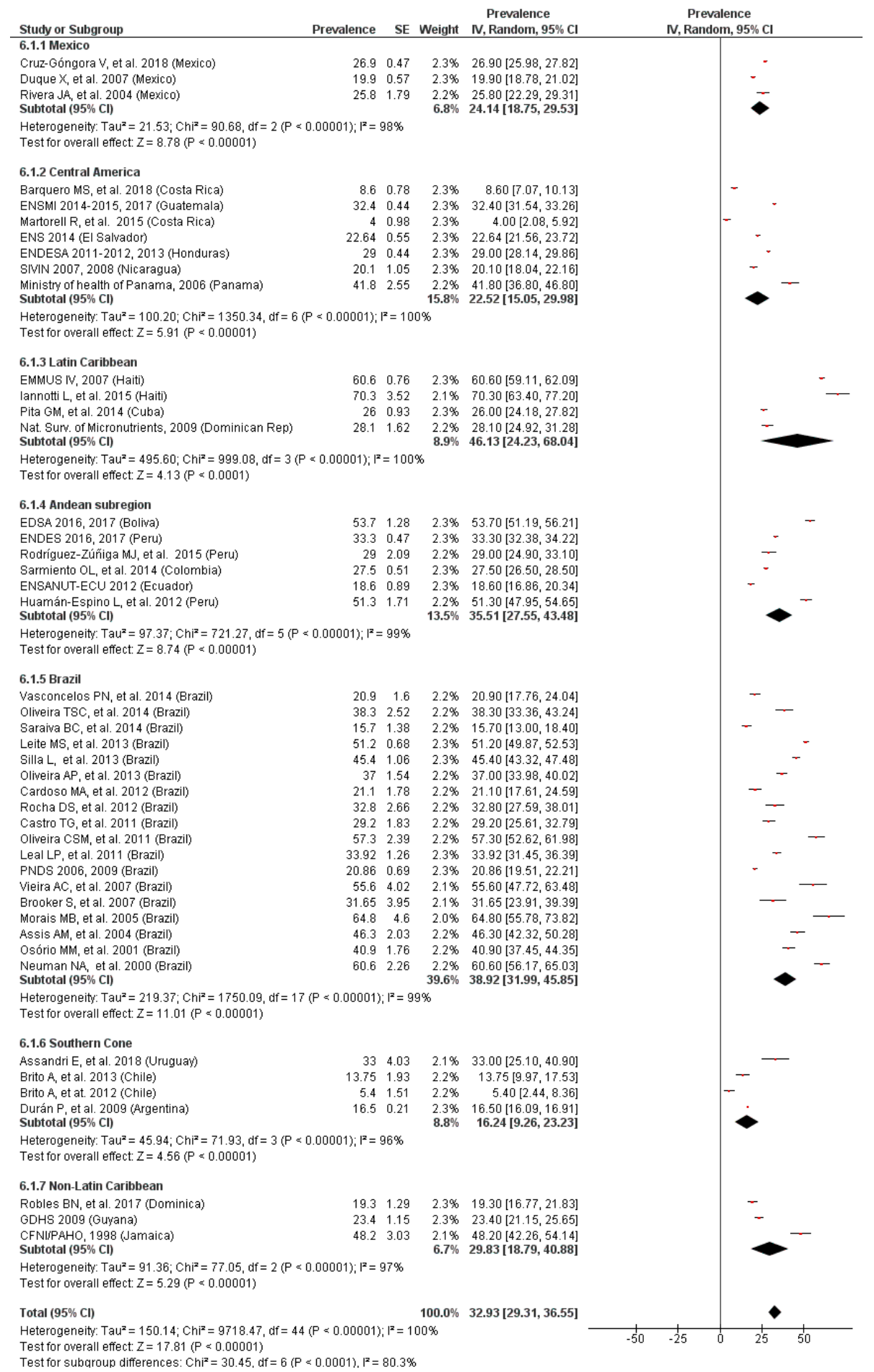

Figure 7. Prevalence of anemia in preschool children by LAC region. 


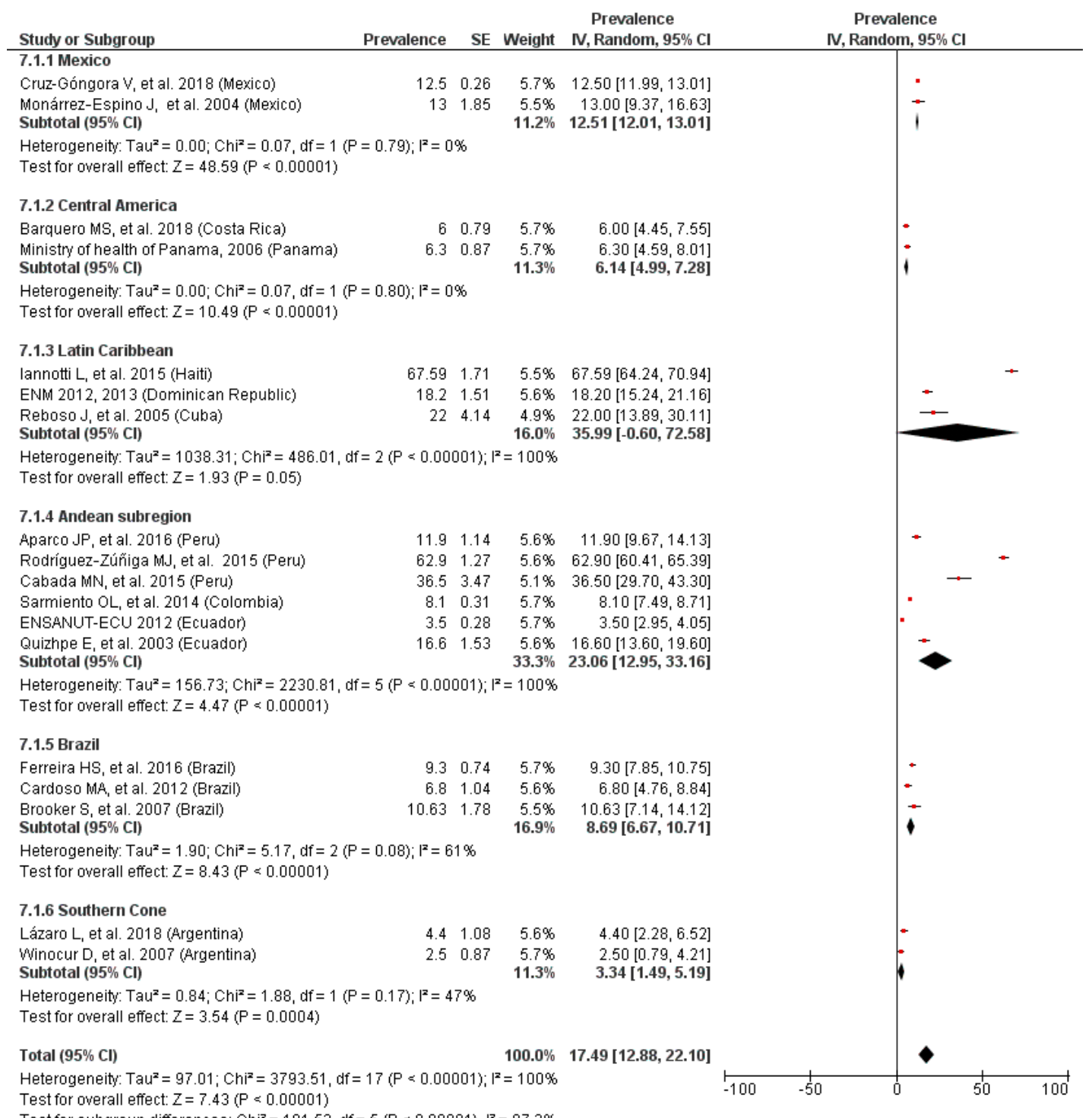

Figure 8. Prevalence of anemia in school-age children by LAC region.

\subsection{Effectiveness of Iron Supplementation Programs}

A subset of 14 articles evaluated the effectiveness of a nutritional intervention and reported data of the prevalence of anemia before and after its application. Iannotti et al. [60] in Haiti, reported data of preschool and school-age children separately. It is worth mentioning that in all cases children belonged to low or very low SES.

The results of the meta-analysis, shown in Figure 9, evidenced how the nutritional intervention reduced $(p<0.01)$ the prevalence of anemia from $45 \%$ to $25 \%$. The heterogeneity was high $\left(\mathrm{I}^{2}=85.8 \%\right)$ in this analysis. The funnel plot reported a possible publication bias. The sensitivity analysis did not show any significant variation in the overall results.

The evaluation of the effectiveness of the interventions carried out at a national level, which included more than 4500 children, showed a significant reduction $(p<0.01)$ in the prevalence of anemia with a decrease from $40 \%$ (95\%CI: $29.02,51.06)$ to $18 \%$ (95\%CI: 8.87, 27.02). The heterogeneity was high for this comparison $\left(\mathrm{I}^{2}=89.1 \%\right)$. On the contrary, the interventions carried out at the regional level or as randomized trials were not as successful $\left(p=0.14, \mathrm{I}^{2}=53.3 \%\right)$ (not shown). 


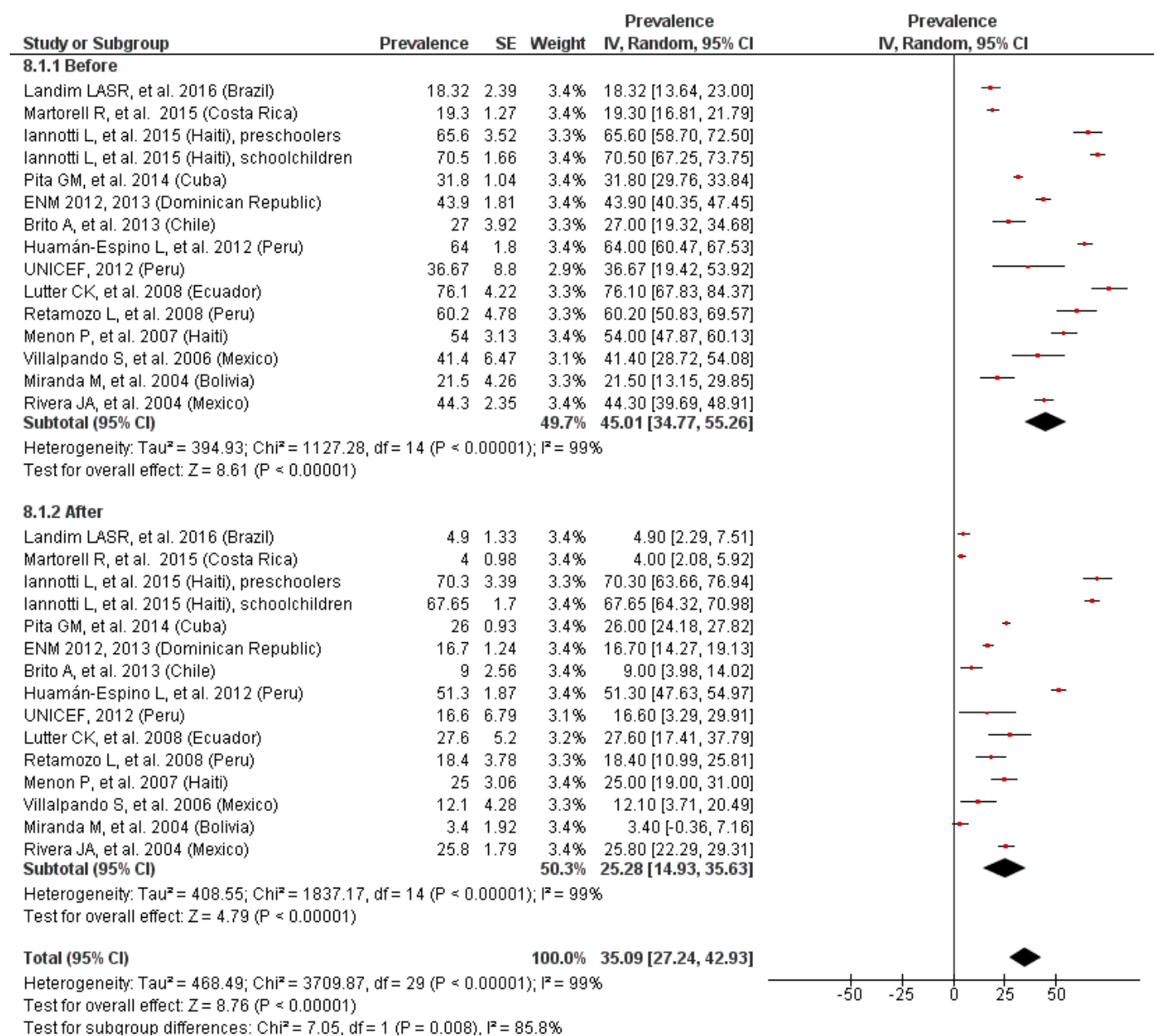

Figure 9. Effectiveness of nutritional intervention programs.

\section{Discussion}

The present study incorporates several notable features. To date, knowledge about the prevalence of anemia in preschool and school-age children in LAC has been made up of isolated data for each country. We conducted a systematic review of the literature to gather the most up-to-date data available on the subject. Furthermore, we used meta-analysis to combine the findings from the identified studies and provide, for the first time, an overall estimate of the prevalence of anemia in more than 160,000 preschoolers and school-age children from 21 LAC countries, through the use of representative studies of fair and high quality, including national surveys.

Notwithstanding, some limitations should also be mentioned. First, moderate and high heterogeneity was observed in the stratified analyses by age, SES, LAC region, and in the meta-analysis of the effectiveness of the nutritional interventions. It could be due to the different number of studies included in each subgroup, variation in sample sizes and age of children among the studies, and the variability in their design. In addition, asymmetry was found in funnel plots of all meta-analyses, which could be attributed to the different methodological quality among the studies or to reporting bias such as publication, language, or citation bias. However, only the studies that followed the standardized diagnostic criteria for anemia, agreed by the WHO and internationally accepted for the studied populations, were included in the systematic review and meta-analyses, which guarantees certain comparability and reinforces the results. With respect to the effectiveness of nutritional interventions, the variability of the types of supplementation and food fortification applied in each case increases the dispersion of the results, undermining, in a certain way, the robustness of this meta-analysis. However, as discussed below, it gives a general idea of how the presence of some 
type of nutritional intervention acts in relation to the prevalence of anemia. This can be considered as a first step in the evaluation of public health policies related to nutrition to achieve increasingly successful interventions.

According to our findings, anemia is still a mild or moderate public health problem in most LAC countries, especially in children. In some countries, it is even a severe public health problem. Although the overall prevalence of anemia in children from LAC is $28.56 \%$, this percentage conceals very different realities, ranging from $3.5 \%$ and $4 \%$ of anemia in Ecuador and Costa Rica, respectively, to $70 \%$ in Haiti. We describe the prevalence of anemia according to sociodemographic conditions and these analyses have allowed us to reveal that pre-school children, especially those from the Caribbean, the Andean subregion, and Brazil, are the population with the highest risk of anemia in LAC. However, children between 5 and 12 years old are not exempt from risk either, especially those with low or very low SES; for this reason, they should be widely included in national surveys and in representative studies on the prevalence of anemia, something that currently does not usually occur. We also assessed the effectiveness of nutritional intervention programs, observing a clear benefit, especially from those at the national level, as we discuss below.

A significant difference in the prevalence of anemia was found according to children's age, the percentage of anemia being higher in preschool children than in school-age ones. The growth rate and nutritional requirements are high until 5 years of age [2,74], which makes young children more vulnerable to malnutrition and vitamin and mineral deficiencies. We also observed that the risk of iron deficiency anemia affected preschool children regardless of their SES, probably because the rapid growth typical of their age occurs in an unfavorable global environment that is not able to meet the child's requirements. In relation to this, poor hygienic conditions, helminth infections, malaria, and the prolonged breastfeeding in replacement of a complete and adequate diet has been related with anemia in young children $[2,75,76]$. However, as children grow, the prevalence of anemia seems to drop off due to the rate of growth and the nutritional requirements slowing down. This was more visible in those school-age children of middle SES, where the social and environmental factors related to anemia could be more controlled. Accordingly, the benefits offered by regions with middle SES, such as increased access to medical care and deworming programs, improved hygienic conditions, and increased food security, could compensate for other factors and result in the difference between middle SES children and those living below the poverty line [2,77].

Although the risk of anemia is patterned by gender throughout the life course, women having a greater prevalence of anemia than men, this circumstance does not occur until puberty [2]. Conversely, anemia appears to be more common in boys than in girls [78,79] at early ages or there is simply not usually gender-related differences in young children [80-82], which agrees with our observations. Furthermore, we neither observed any differences between girls aged 9 to 12 years old and boys at these ages, contrary to the premise that menstrual blood losses could increase the risk of anemia in girls [2].

The nutritional transition that LAC has undergone during the last three decades and is still being experienced by some countries [83-85] could be the reason for the unexpected lack of effect of rurality on the prevalence of anemia, as has historically occurred. Although we observed that anemia was less frequent in urban than in rural areas, especially in school-age children $(16.86 \%$; $95 \%$ CI: 6.93 , 26.80 , and $25.87 \%$; 95\%CI: 6.50, 45.25, respectively), the association was not significant ( $p=0.42$ ). This suggested that despite the diet of children living in cities possibly being wider and more varied than in rural areas, it is increasingly based on processed foods, rich in sugars and fats, which do not contain a sufficient amount of iron and other vitamins and minerals. Along with sedentary lifestyle linked to urban environments, this rapid change in dietary patterns provides an obstacle when it comes to reducing anemia in cities, despite the greater availability of food.

In order to address the public health problem posed by anemia, several intervention programs and health policies have been implemented during the last two decades in LAC countries. After this systematic review, we observed that these actions tend to focus on young children as the most 
vulnerable population group and often neglect children over 5 years of age. This is something that should be corrected, having observed that school-age children are also at risk of anemia, especially those from low-income regions. As anemia is caused mainly by iron deficiency $[1,3]$, the health strategies launched had a marked nutritional aspect. Food delivery, distribution of micronutrient powders and iron supplements, and fortification of staple foods are the most frequent form of nutritional intervention [2]. Costa Rica has been a pioneer in mass food fortification including wheat flour, maize flour, and liquid and powdered milk since 1999 [53], which could explain the low prevalence of anemia among Costa Rican children. According to our results, anemia was not a concern either, or it was simply a mild public health problem, for children in Chile and Argentina. It was likely a consequence of the national plans launched by the countries of the Southern Cone since 2000. In Chile, the National Complementary Feeding Program [52] was based on iron fortification of powdered milk, while Argentina implemented, in addition, fortification of wheat flour and iron supplementation for children under 2 years of age [3]. In addition to food fortification, Cuba [55] and the Dominic Republic [25] included food delivery in their national plans to improve the availability and diversity of food in the general population. In addition, Mexico [61] and Peru [69] implemented comprehensive plans involving health services, nutritional and health education, and even cash transfers. Good results were reported after these interventions on a larger scale; the prevalence of anemia was reduced from 32 to $26 \%$ in Cuba, from 44 to $17 \%$ and $26 \%$ in the Dominican Republic and Mexico, respectively, and even decreased by more than 40 percentage points in Peru. These achievements suggested, therefore, that not only nutritional deficiencies but the global social and household environment could determine the risk of anemia in children [72,77].

On the other hand, considering LAC regions, the Latin Caribbean and especially Haiti [60] lead the list in terms of the prevalence of anemia, representing a severe public health problem for young children. It should be noted that the Haitian government has never established a national plan to reduce anemia [86], and it has been documented that regional interventions with milk or complementary foods fortified with iron have generally not been successful, although some isolated positive results were found [71]. In a similar way, Jamaica [59], Panama [14], and some regions of Brazil [28,38,43-49] also exceeded $40 \%$ prevalence of anemia. However, there is no record of any nutrition intervention program in Jamaica, and, in the case of Brazil, some reports highlight the low coverage and inadequate compliance with the National Iron Supplement Program approved by the government in 2005 [87,88]. As to Panama, the National Plan for the Prevention and Control of Micronutrient Deficiencies was active between 2008 and 2015, but there are no data available to date on the observed effects on the prevalence of anemia [89].

Following the nutritional intervention programs, some countries continued to have high rates of anemia [60,65], while others reduced its prevalence significantly [52,67,70-73]. Although similar actions were carried out in Haiti [60,71], Brazil [72], Bolivia [70], Peru [65,68], Ecuador [67], Mexico [73], and Chile [52], their effectiveness seems not to be the same. The success or failure of health and nutritional interventions, especially in populations with low or very low SES, has been related with multiple causes, including coverage, participant compliance, monitoring, and quality in reporting results $[2,90]$. This could therefore explain our observation that, although some regional or local studies showed good results at the individual level, jointly, only those programs designed at a national level, with great coverage, well monitored, and extended over time had success in reducing the prevalence of anemia in the children of the LAC countries.

\section{Conclusions}

Anemia remains a public health problem for children in LAC countries, especially for children under 5 years old. The implementation, expansion, and good monitoring of nutritional intervention programs at the national level are needed to control anemia. They should be designed to address the direct and indirect determinants of anemia, according to the specific needs of children in each country. 
Author Contributions: The authors' responsibilities were as follows-V.A.: designed the study; L.I.V., M.V., and E.V.: conducted the literature review, analyzed data, and discussed the results; M.T. and V.A.: supported data interpretation and discussion; L.I.V. and E.V.: wrote the manuscript; V.A.: had primary responsibility for the final content of the manuscript; and all authors: read, revised, and approved the final manuscript.

Funding: This research received no external funding.

Conflicts of Interest: The authors declare no conflict of interest.

\section{References}

1. De Benoist, B.; McLean, E.; Egli, I.; Cogswell, M. Worldwide Prevalence of Anaemia 1993-2005: WHO Global Database on Anaemia; WHO: Geneva, Switzerland, 2008.

2. World Health Organization. Nutritional Anaemias: Tools for Effective Prevention; WHO: Geneva, Switzerland, 2017.

3. Pan American Health Organization. Anemia in Latin America and the Caribbean, 2009; PAHO: Washington, DC, USA, 2010.

4. Best, C.; Neufingerl, N.; van Geel, L.; van den Briel, T.; Osendarp, S. The nutritional status of school-aged children: Why should we care? Food Nutr. Bull. 2014, 31, 400-417. [CrossRef] [PubMed]

5. Soliman, A.; de Sanctis, V.; Kalra, S. Anemia and growth. Indian J. Endocrinol. Metab. 2014, 18, 1-5. [CrossRef]

6. Lozoff, B.; Corapci, F.; Burden, M.J.; Kaciroti, N.; Angulo-Barroso, R.; Sazawal, S.; Black, M. Preschool-aged children with iron deficiency anemia show altered affect and behavior. J. Nutr. 2007, 137, 683-689. [CrossRef]

7. Balarajan, Y.; Ramakrishnan, U.; Özaltin, E.; Shankar, A.H.; Subramanian, S.V. Anaemia in low-income and middle-income countries. Lancet 2011, 378, 2123-2135. [CrossRef]

8. Zavaleta, N.; Astete-Robilliard, L. Effect of anemia on child development: Long-term consequences. Rev. Peru. Med. Exp. Salud Publica 2017, 34, 716-722. [CrossRef]

9. Galicia, L.; Grajeda, R.; de Romaña, D.L. Nutrition situation in Latin America and the Caribbean: Current scenario, past trends, and data gaps. Pan Am. J. Public Health 2016, 40, 104-113.

10. Stroup, D.F.; Berlin, J.A.; Morton, S.C.; Olkin, I.; Williamson, G.D.; Rennie, D.; Moher, D.; Becker, B.J.; Sipe, T.A.; Thacker, S.B. Meta-analysis of observational studies in epidemiology: A proposal for reporting. Meta-analysis of observational studies in epidemiology (MOOSE) group. JAMA 2000, 283, 2008-2012. [CrossRef] [PubMed]

11. Wells, G.A.; Shea, B.; O'Connell, D.; Peterson, J.; Welch, V.; Losos, M.; Tugwell, P. The Newcastle-Ottawa Scale (NOS) for Assessing the Quality of Nonrandomized Studies in Meta-Analyses. 2013. Available online: http:/ / www.ohri.ca/programs/clinical_epidemiology/oxford.asp (accessed on 12 November 2018).

12. Higgins, J.P.; Thompson, S.G. Quantifying heterogeneity in a meta-analysis. Stat. Med. 2002, 21, 1539-1558. [CrossRef] [PubMed]

13. Noel Robles, B.; James, A.B.; Macri, R.; Xiong, M.; Jafri, S.; Vitale, A.; Beata, V.; Faheem, S.; McIntyre-Francis, R. Prevalence of anemia in preschool aged children living in Dominica. J. Pediatr. Care 2017, 3, 12. [CrossRef]

14. UNICEF; PAHO; Ministry of Health of Panama. Situation of Deficiency of Iron and Anemia; UNICEF; PAHO; Ministry of Health of Panama: Panama, Republic of Panama, 2006.

15. National Institute of Statistics and Informatics. Demographic and Family Health Survey (ENDES 2016); National Institute of Statistics and Informatics: Lima, Peru, 2016.

16. Freire, W.B.; Ramírez-Luzuriaga, M.J.; Belmont, P.; Mendieta, M.J.; Silva-Jaramillo, M.K.; Romero, N.; Sáenz, K.; Piñeiros, P.; Gómez, L.F.; Monge, R. Vol. I: National Survey of Health and Nutrition (ENSANUT-ECU 2012); Ministry of Public Health, National Institute of Statistics and Census: Quito, Ecuador, 2014.

17. Cayemites, M.; Placide, M.F.; Mariko, S.; Barrère, B.; Sévère, B.; Alexandre, C. Enquête Mortalité, Morbidité et Utilisation des Services (EMMUS-IV) 2005-2006; Ministère de la Santé Publique et de la Population, Institut Haïtien de l'Enfance et Macro International Inc.: Calverton, MD, USA, 2007.

18. Ministry of Health; Brazilian Center for Analysis and Planning. National Survey on Demography and Health of Women and Children (PNDS 2006): Dimensions of Reproduction and Child Health; Ministry of Health: Brasilia, Brazil, 2009.

19. Ministry of Health (Honduras), National Institute of Statistics and ICF International. National Survey of Demography and Health (ENDESA 2011-2012); Ministry of Health: Tegucigalpa, Honduras, 2012.

20. Ministry of Health [Guyana], Bureau of Statistics and ICF Macro. Guyana Demographic and Health Survey 2009; Ministry of Health: Georgetown, Guyana, 2010. 
21. WHO Global Database on Anaemia: Vitamin and Mineral Nutrition Information System [Nicaragua]. Available online: https://www.who.int/vmnis/anaemia/data/database/countries/nic_ida.pdf?ua=1 (accessed on 26 February 2010).

22. Ministry of Public Health and Social Assistance; Statistics National Institute; ICF International. VI National Survey of Maternal and Child Health (ENSMI 2014-2015); Ministry of Public Health and Social Assistance: Guatemala City, Guatemala, 2017.

23. Salvadoran Demographic Association; ICC; CDC. National Survey of Family Health (FESAL 2008); Salvadoran Demographic Association: San Salvador, Republic of El Salvador, 2009.

24. Ministry of Public Health and Social Assistance. National Micronutrient Survey; Dominican Republic: Santo Domingo, Dominican Republic, 2014.

25. Ministry of Education [Dominican Republic]; INABIE; UNICEF; PMA; PNUD. National Micronutrient Survey in the School Population of the Dominican Republic (ENM 2012); Dominican Republic: Santo Domingo, Dominican Republic, 2013.

26. Ministry of Health (Bolivia); Statistics National Institute. Demography and Health Survey (EDSA 2016); Ministry of Health: La Paz, Bolivia, 2017.

27. Sarmiento, O.L.; Parra, D.C.; González, S.A.; González-Casanova, I.; Forero, A.Y.; Garcia, J. The dual burden of malnutrition in Colombia. Am. J. Clin. Nutr. 2014, 100, 1628S-1635S. [CrossRef] [PubMed]

28. Leite, M.S.; Cardoso, A.M.; Coimbra, C.E., Jr.; Welch, J.R.; Gugelmin, S.A.; Lira, P.C.; Horta, B.L.; Santos, R.V.; Escobar, A.L. Prevalence of anemia and associated factors among indigenous children in Brazil: Results from the First National Survey of Indigenous People's Health and Nutrition. Nutr. J. 2013, 12, 69. [CrossRef] [PubMed]

29. Durán, P.; Mangialavori, G.; Biglieri, A.; Kogan, L.; Abeyá Gilardon, E. Nutrition status in Argentinean children 6 to 72 months old. Results from the National Nutrition and Health Survey (ENNyS). Arch. Argent Pediatr. 2009, 107, 397-404.

30. De la Cruz-Góngora, V.; Villalpando, S.; Shamah-Levy, T. Prevalence of anemia and consumption of iron-rich food groups in Mexican children and adolescents: Ensanut MC 2016. Salud Publica Mex 2018, 60, 291-300. [CrossRef] [PubMed]

31. Duque, X.; Flores-Hernández, S.; Flores-Huerta, S.; Méndez-Ramírez, I.; Muñoz, S.; Turnbull, B.; Martínez-Andrade, G.; Ramos, R.I.; González-Unzaga, M.; Mendoza, M.E.; et al. Prevalence of anemia and deficiency of iron, folic acid, and zinc in children younger than 2 years of age who use the health services provided by the Mexican Social Security Institute. BMC Public Health 2007, 7, 345. [CrossRef] [PubMed]

32. Winocur, D.; Ceriani Cernadas, J.M.; Imach, E.; Otasso, J.C.; Morales, P.; Gards, A. Prevalence of iron deficiency anemia in a group of pre-school and school children, living in conditions of poverty. Medicina (B. Aires) 2004, 64, 481-486. [PubMed]

33. Lázaro Cuesta, L.; Rearte, A.; Rodríguez, S.; Niglia, M.; Scipioni, H.; Rodríguez, D.; Salinas, R.; Sosa, C.; Rasse, S. Anthropometric and biochemical assessment of nutritional status and dietary intake in school children aged 6-14 years, Province of Buenos Aires, Argentina. Arch. Argent. Pediatr. 2018, 116, e34-e46. [PubMed]

34. Leal, L.P.; Batista Filho, M.; Cabral de Lira, P.I.; Natal Figueiroa, J.; Osório, M.M. Prevalence of anemia and associated factors in children aged 6-59 months in Pernambuco, Northeastern Brazil. Rev. Saude Publica 2011, 45, 457-466. [CrossRef]

35. Cardoso, M.A.; Scopel, K.K.; Muniz, P.T.; Villamor, E.; Ferreira, M.U. Underlying factors associated with anemia in amazonian children: A population-based, cross-sectional study. PLoS ONE 2012, 7, e36341. [CrossRef]

36. Rocha, D.S.; Capanema, F.D.; Pereira Netto, M.; Franceschini, S.C.; Lamounier, J.A. Prevalence and risk factors of anemia in children attending daycare centers in Belo Horizonte-MG. Rev. Bras. Epidemiol. 2012, 15, 675-684. [CrossRef]

37. De Oliveira, A.P.; Pascoal, M.N.; dos Santos, L.C.; Pereira, S.C.; Justino, L.E.; Petarli, G.B.; Kitoko, P.M. The prevalence of anemia and its association with socio-demographic and anthropometric aspects in children living in Vitória, State of Espírito Santo, Brazil. Ciênc. Saude Colet. 2013, 18, 3273-3280.

38. Silla, L.M.; Zelmanowicz, A.; Mito, I.; Michalowski, M.; Hellwing, T.; Shilling, M.A.; Friedrisch, J.R.; Bittar, C.M.; Albrecht, C.A.; Scapinello, E.; et al. High prevalence of anemia in children and adult women in an urban population in southern Brazil. PLoS ONE 2013, 8, e68805. [CrossRef] [PubMed] 
39. De Oliveira, T.S.C.; da Silva, M.C.; Santos, J.N.; Rocha, D.S.; Alves, C.R.L.; Capanema, F.D.; Lamounier, J.A. Anemia entre pré-escolares-um problema de saúde pública em Belo Horizonte, Brasil. Ciênc. Saude Colet. 2014, 19, 59-66. [CrossRef] [PubMed]

40. Saraiva, B.C.; Soares, M.C.; Santos, L.C.; Pereira, S.C.; Horta, P.M. Iron deficiency and anemia are associated with low retinol levels in children aged 1 to 5 years. J. Pediatr. 2014, 90, 593-599. [CrossRef]

41. Vasconcelos, P.N.; Cavalcanti, D.S.; Leal, L.P.; Osório, M.M.; Batista Filho, M. Time trends in anemia and associated factors in two age groups (6-23 and 24-59 months) in Pernambuco State, Brazil, 1997-2006. Cad. Saude Publica 2014, 30, 1777-1787. [CrossRef] [PubMed]

42. Da Silva Ferreira, H.; de Assunção Bezerra, M.K.; Lopes De Assunção, M.; Egito de Menezes, R.C. Prevalence of and factors associated with anemia in school children from Maceió, northeastern Brazil. BMC Public Health 2016, 16, 380. [CrossRef]

43. Neuman, N.A.; Tanaka, O.Y.; Szarfarc, S.C.; Guimarães, P.R.; Victora, C.G. Prevalence and risk factors for in Southern Brazil. Rev. Saude Publica 2000, 34, 56-63. [CrossRef] [PubMed]

44. Osório, M.M.; Lira, P.I.; Batista-Filho, M.; Ashworth, A. Prevalence of anemia in children 6-59 months old in the state of Pernambuco, Brazil. Rev. Panam. Salud Pública 2001, 10, 101-107. [CrossRef] [PubMed]

45. Assis, A.M.; Barreto, M.L.; Gomes, G.S.; Prado, M.S.; dos Santos, N.S.; Santos, L.M.; Sampaio, L.R.; Ribeiro, R.C.; de Oliveira, L.P.; de Oliveira, V.A. Childhood anemia prevalence and associated factors in Salvador, Bahia, Brazil. Cad. Saude Publica 2004, 20, 1633-1641. [CrossRef] [PubMed]

46. Morais, M.B.; Alves, G.M.; Fagundes-Neto, U. Nutritional status of Terena indian children from Mato Grosso do Sul, Brazil: Follow up of weight and height and current prevalence of anemia. J. Pediatr. 2005, 81, 383-389. [CrossRef]

47. Brooker, S.; Jardim-Botelho, A.; Quinnell, R.J.; Geiger, S.M.; Caldas, I.R.; Fleming, F.; Hotez, P.J.; Correa-Oliveira, R.; Rodrigues, L.C.; Bethony, J.M. Age-related changes in hookworm infection, anaemia and iron deficiency in an area of high Necator americanus hookworm transmission in south-eastern Brazil. Trans. R. Soc. Trop. Med. Hyg. 2007, 101, 146-154. [CrossRef]

48. Vieira, A.C.; Diniz, A.S.; Cabral, P.C.; Oliveira, R.S.; Lóla, M.M.F.; Silva, S.M.; Kolsteren, P. Nutritional assessment of iron status and anemia in children under 5 years old at public daycare centers. J. Pediatr. 2007, 83, 370-376. [CrossRef]

49. Oliveira, C.S.M.; Cardoso, M.A.; Araújo, T.S.; Muniz, P.T. Anemia em crianças de 6 a 59 meses e fatores associados no Município de Jordão, Estado do Acre, Brasil. Cad. Saude Publica 2011, 27, 1008-1020. [CrossRef]

50. De Castro, T.G.; Silva-Nunes, M.; Conde, W.L.; Muniz, P.T.; Cardoso, M.A. Anemia and iron defi ciency among schoolchildren in the Western Brazilian Amazon: Prevalence and associated factors. Cad. Saude Publica 2011, 27, 131-142. [PubMed]

51. Brito, A.; Hertrampf, E.; Olivares, M. Low prevalence of anemia in children aged 19 to 72 months in Chile. Food Nutr. Bull. 2012, 33, 308-311. [CrossRef] [PubMed]

52. Brito, A.; Olivares, M.; Pizarro, T.; Rodríguez, L.; Hertrampf, E. Chilean Complementary Feeding Program reduces anemia and improves iron status in children aged 11 to 18 months. Food Nutr. Bull. 2013, 34, 378-385. [CrossRef]

53. Martorell, R.; Ascencio, M.; Tacsan, L.; Alfaro, T.; Young, M.F.; Addo, O.Y.; Dary, O.; Flores-Ayala, R. Effectiveness evaluation of the food fortification program of Costa Rica: Impact on anemia prevalence and hemoglobin concentrations in women and children. Am. J. Clin. Nutr. 2015, 101, 210-217. [CrossRef] [PubMed]

54. Barquero, M.S.; Mora, A.M.; Santamaría-Ulloa, C.; Marín Arias, L.; Granados Zamora, M.; Reyes Lizano, L. Nutritional Deficiencies and Anemia in Preschool Children of Costa Rica in 2014-2016. 2018. Available online: https:/ / revistas.ucr.ac.cr/index.php/psm/article/view/32447 (accessed on 10 December 2018).

55. Pita, G.M.; Jiménez, S.; Basabe, B.; García, R.G.; Macías, C.; Selva, L.; Hernández, C.; Cruz, M.; Herrera, R.; O'Farrill, R.; et al. Anemia in children under five years old in Eastern Cuba, 2005-2011. MEDICC Rev. 2014, 16, 16-23.

56. Reboso Pérez, J.; Cabrera Núñez, E.; Rodríguez, G.P.; Jiménez Acosta, S. Anemia por deficiencia de hierro en niños de 6 a 24 meses y de 6 a 12 años de edad. Revista Cubana de Salud Pública 2005, 31, 306-312.

57. Quizhpe, E.; San Sebastián, M.; Hurtig, A.K.; Llamas, A. Prevalence of anemia in schoolchildren in the Amazon area of Ecuador. Rev. Panam. Salud Pública 2003, 13, 355-361. [CrossRef] 
58. Assandri, E.; Skapino, E.; da Rosa, D.; Alemán, A.; Acuña, A.M. Anemia, nutritional status and intestinal parasites in children from vulnerable homes of Montevideo. Arch. Pediatr. Urug. 2018, 89, 86-98.

59. Ministry of Education [Jamaica]; Ministry of Health [Jamaica]; PAHO. Micronutrient Study Report: An Assessment of the Vitamin A, E, Betacarotene, and Iron Status in Jamaica; PAHO: Kingston, Jamaica, 1998.

60. Iannotti, L.L.; Delnatus, J.R.; Odom, A.R.; Eaton, J.C.; Griggs, J.J.; Brown, S.; Wolff, P.B. Determinants of anemia and hemoglobin concentration in haitian school-aged children. Am. J. Trop. Med. Hyg. 2015, 93, 1092-1098. [CrossRef]

61. Rivera, J.A.; Sotres-alvarez, D.; Habicht, J.P.; Shamah, T.; Villalpando, S. Impact of the Mexican program for education, health, and nutrition (Progresa) on rates of growth and anemia in infants and young children a randomized effectiveness study. JAMA 2004, 291, 2563-2570. [CrossRef] [PubMed]

62. Monárrez-Espino, J.; Martínez, H.; Martínez, V.; Greiner, T. Nutritional status of indigenous children at boarding schools in northern Mexico. Eur. J. Clin. Nutr. 2004, 58, 532-540. [CrossRef] [PubMed]

63. Cabada, M.M.; Goodrich, M.R.; Graham, B.; Villanueva-Meyer, P.G.; Deichsel, E.L.; Lopez, M.; Arque, E.; Clinton White, A., Jr. Prevalence of intestinal helminths, anemia, and malnutrition in Paucartambo, Peru. Rev. Panam. Salud Publica 2015, 37, 69-75. [PubMed]

64. Aparco, J.P.; Bautista-Olórtegui, W.; Astete-Robilliard, L.; Pillaca, J. Assessment of the nutritional status, physical activity, and eating habits of schoolchildren in Cercado de Lima. Rev. Peru. Med. Exp. Salud Publica 2016, 33, 633-639. [CrossRef]

65. Huamán-Espino, L.; Aparco, J.P.; Nuñez-Robles, E.; Gonzáles, E.; Pillaca, J.; Mayta-Tristán, P. Consumo de suplementos con multimicronutrientes Chispitas* y anemia en niños de 6 a 35 meses: Estudio transversal en el contexto de una intervención poblacional en Apurímac, Perú. Rev. Peru. Med. Exp. Salud Publica 2012, 29, 314-323. [CrossRef] [PubMed]

66. RODRÍGUEZ-ZÚÑIGA, M.J. Obesidad, sobrepeso y anemia en niños de una zona rural de lima, Perú. MEDICINA (Buenos Aires) 2015, 75, 379-383.

67. Lutter, C.K.; Rodriguez, A.; Fuenmayor, G.; Avila, L.; Sempertegui, F.; Escobar, J. Growth and micronutrient status in children receiving a fortified complementary food. J. Nutr. 2008, 138, 379-388. [CrossRef]

68. UNICEF. ADIÓS ANEMIA: A Local Strategy for the Reduction of Childhood Anemia in Peri-Urban Areas; UNICEF: Lima, Peru, 2012.

69. PMA; PRONAA. Educational Intervention in Prevention of Anemia and Malnutrition in Pachacutec-Peru; PMA; PRONAA: Lima, Peru, 2008.

70. Miranda, M.; Olivares, M.; Brito, A.; Pizarro, F. Reducing iron deficiency anemia in Bolivian school children: Calcium and iron combined versus iron supplementation alone. Nutrition 2014, 30, 771-775. [CrossRef]

71. Menon, P.; Ruel, M.T.; Loechl, C.U.; Arimond, M.; Habicht, J.P.; Pelto, G.; Michaud, L. Micronutrient Sprinkles Reduce Anemia among 9-to 24-Mo-Old Children When Delivered through an Integrated Health and Nutrition Program in Rural Haiti. J. Nutr. 2007, 137, 1023-1030. [CrossRef]

72. Landim, L.A.; Pessoa, M.L.; Brandão, A.C.; Morgano, M.A.; Mota Araújo, M.A.; Rocha, M.M.; Arêas, J.A.; Moreira-Araújo, R.S. Impact of the two different iron fortified cookies on treatment of anemia in preschool children in Brazil. Nutr. Hosp. 2016, 33, 1142-1148. [CrossRef] [PubMed]

73. Villalpando, S.; Shamah, T.; Rivera, J.A.; Lara, Y.; Monterrubio, E. Fortifying milk with ferrous gluconate and zinc oxide in a public nutrition program reduced the prevalence of anemia in toddlers. J. Nutr. 2006, 136, 2633-2637. [CrossRef]

74. Kliegman, R.M.; Stanton, B.F.; Geme, J.W.; Schor, N.F. Nelson. Textbook of Pediatrics, 20th ed.; Elsevier: Barcelona, Spain, 2016; pp. 68-88.

75. Meinzen-Derr, J.K.; Guerrero, M.L.; Altaye, M.; Ortega-Gallegos, H.; Ruiz-Palacios, G.M.; Morrow, A.L. Risk of infant anemia is associated with exclusive breast-feeding and maternal anemia in a mexican cohort. J. Nutr. 2006, 136, 452-458. [CrossRef]

76. Wang, F.; Liu, H.; Wan, Y.; Li, J.; Chen, Y.; Zheng, J.; Huang, T.; Li, D. Prolonged exclusive breastfeeding duration is positively associated with risk of anemia in infants aged 12 months. J. Nutr. 2016, 146, 1707-1713. [CrossRef] [PubMed]

77. Nriagu, J.O. Encyclopedia of Environmental Health; Elsevier: Michigan, MI, USA, 2011; pp. 601-610.

78. Joo, E.Y.; Kim, K.Y.; Kim, D.H.; Lee, J.E.; Kim, S.K. Iron deficiency anemia in infants and toddlers. Blood Res. 2016, 51, 268-273. [CrossRef] [PubMed] 
79. Lozoff, B.; Kaciroti, N.; Walter, T. Iron deficiency in infancy: Applying a physiologic framework for prediction. Am. J. Clin. Nutr. 2006, 84, 1412-1421. [CrossRef]

80. Diouf, S.; Folquet, M.; Mbofung, K.; Ndiaye, O.; Brou, K.; Dupont, C.; N'dri, D.; Vuillerod, M.; Azaïs-Braesco, V.; Tetanye, E. Prevalence and determinants of anemia in young children in French-speaking Africa. Role of iron deficiency. Arch. Pédiatr. 2015, 22, 1188-1197. [CrossRef] [PubMed]

81. Wieringa, F.T.; Berger, J.; Dijkhuizen, M.A.; Hidayat, A.; Ninh, N.X.; Utomo, B.; Wasantwisut, E.; Winichagoon, P. Sex differences in prevalence of anaemia and iron deficiency in infancy in a large multi-country trial in South-East Asia. Br. J. Nutr. 2018, 98, 1070-1076. [CrossRef] [PubMed]

82. Ncogo, P.; Romay-Barja, M.; Benito, A.; Aparicio, P.; Nseng, G.; Berzosa, P.; Santana-Morales, M.A.; Riloha, M.; Valladares, B.; Herrador, Z. Prevalence of anemia and associated factors in children living in urban and rural settings from Bata District, Equatorial Guinea, 2013. PLoS ONE 2017, 12, e0176613. [CrossRef]

83. Barría, P.; Amigo, H. Nutritional transition: A review of the Latin American profile. Arch. Latinoam. Nutr. 2006, 56, 3-11.

84. Albala, C.; Vio, F.; Kain, J.; Uauy, R. Nutrition transition in Latin America: The case of Chile. Nutr. Rev. 2009, 59, 170-176. [CrossRef]

85. Bermudez, O.I.; Tucker, K.L. Trends in dietary patterns of Latin American populations. Cad. Saude Publica 2003, 19, S87-S99. [CrossRef] [PubMed]

86. Mujica-Coopman, M.F.; Brito, A.; López de Romaña, D.; Ríos-Castillo, I.; Coris, H.; Olivares, M. Prevalence of anemia in Latin America and the Caribbean. Food Nutr. Bull. 2015, 36, S119-S128. [CrossRef] [PubMed]

87. Cembranel, F.; Corso, A.C.T.; González-Chica, D.A. Inadequacies in the treatment of iron deficiency anemia among children registered in the national program of iron supplementation in Florianopolis, Santa Catarina, Brazil. Texto Contexto Enferm. 2017, 26, e06310015. [CrossRef]

88. Cembranel, F.; Corso, A.C.T.; González-Chica, D.A. Coverage and adequacy of ferrous sulfate supplementation in the prevention of anemia among children treated at health centers of Florianopolis, Santa Catarina. Rev. Paul. Pediatr. 2013, 31, 315-323. [CrossRef] [PubMed]

89. Ministry of Health [Panama]; National Commission of Micronutrients. National Plan "Prevention and Control of Micronutrient Deficiencies" 2008-2015; Ministry of Health: Panama, Republic of Panama, 2008.

90. World Health Statistics 2010; WHO: Geneva, Switzerland. Available online: http://www.who.int/iris/ handle/10665/44292 (accessed on 2 December 2018). 